\section{Gender Differences in Self-Concept Among a Sample of Students of the United States International University in Africa}

\section{Abstract}

Background: Self-concept is a multifaceted belief system where self-evaluation is carried out in relation to one's environment. Various research studies have found that self-concept has an impact on the psychological, physical and social wellbeing of a person. There is a dearth of studies on the relationship between self-concept and gender among students in private universities in Kenya. The purpose of this study is to investigate the relationship between gender and self-concept among a sample of United States International University-Africa (USIU-A) students.

Methods: The study was conducted in a sample of students studying either the psychology of personality or abnormal psychology courses. The sample size $(n)$ for the current study is 57 : which is $0.87 \%$ of the student population in the USIU-A. The methodology used in this study is the Tennessee Self-concept Scale (TSCS) consisting of 82 statements. The regression analysis of the six dimensions of selfconcept and gender was done using SPSS $^{\circledR}$ (Version 23).

Results: The current study found that personal self-concept variables explained $46.8 \%$ of the variations of overall self-concept. A regression between overall selfconcept rating and gender revealed that overall self-concept increases by $6.381 \%$ as gender changes from female to male.

Conclusion: Male participants were found to have a higher overall self-concept than female participants. Among the sexes the highly suggested ways of increasing self-concept were through socialization, reading and self-awareness.

Keywords: Gender; Self-concept; Self-evaluation; Self-awareness

\section{Rose Nabi Deborah Karimi Muthuri* and Josephine Nyaboke Arasa}

Department of Psychology, United States International University in Africa, P. O. Box 14634-00800, Nairobi, Kenya.

Corresponding author:

Rose Nabi Deborah Karimi Muthuri

\section{”nabideborah18@gmail.com}

Department of Psychology, United States International University in Africa (USIU-A), P.O. Box 14634-00800, Nairobi, Kenya.

Tel: +254 730116000

Citation: Muthuri RNDK, Arasa JN (2017) Gender Differences in Self-Concept Among a Sample of Students of the United States International University in Africa. Ann Behav Sci. Vol. 3 No. 2:7

Received: July 20, 2017; Accepted: August 11, 2017; Published: August 15, 2017

\section{Introduction}

According to William James theory of Self, he states that the self is developed through social interaction and is based on the social character of the human language [1]. The self occurs as a result of revolution of cognition [1]. James explains that the self

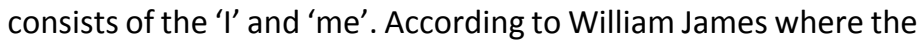
' $I$ ' self represents the subjective and explicit self that is active [2]. The 'me' self is implicit and reflective when perceiving. It is the implicit self or 'me' that the self-concept exists [2]. In psychology there are various elements under self-concept such self-esteem, self-awareness, self-image and self-evaluation.

In 2016, Goldman and Penner suggested that the self-concept of an individual their perception of success in any dimension of self-concept [3]. The self-concept is comprised of six dimensions including, physical, moral, social, personal, academic and family [1]. Self-concept is a multifaceted belief system where selfevaluation is done in relation to the environment [4]. Researchers stated that feeling of negative self-concept results in poor health, increased psychological issues and eventually more social problems [5].

The self-concept is beyond the physical appearance of an individual. It is comprised of spatial and temporal continuity [1]; in addition, to the terms through which they evaluate the self. Researchers claim that it is important for individuals to maintain the internal consistency of the self; in order to determine the individual interpretation of their experience and the level of expectation of the individual [6]. Similarly, the internal 
consistency can be seen as the well-being of an individuals. In 2016, Chui and Wong discovered that an individual's wellbeing is dependent on their self-perception [7].

According to social psychologists, self-concept can be divided into two: self-conception and self-evaluation [1]. The self-conception links the self to the social system [1]. Self-evaluation is about the judgments made on the basis of substantive aspects of selfconcepts such as self-esteem [1].

Acquiring self-concept is similar to the acquisition of selfknowledge. Through getting self-esteem and body image an individual develops self-concept [5]. According to Grecas, selfconcept is ever changing and social psychologists claim that it goes through rebirth or renaissance as individuals grow [1]. The experiences an individual goes through as they grow result in the change of self. Self-concept presents both the conception of one's identity and the societal structure and persona [1].

Self-concept develops throughout the lifespan of an individual [8]. Through one's life span self-esteem of an individual also changes; thus, their self-concept is also altered [9]. From childhood we normally begin with high self-esteem, which deteriorates with ageing [8].

Researchers have found various factors that influence selfconcept. For instance, feedback is an extremely essential component of the development of self-concept [9]. In India, the environment of childrearing such as an institution was found to have a negative effect on the development of the self-concept of an individual [10]. In China, a study found regional differences in rating of self-concept among university students [4]. In 2005, it was found that the executive self is influenced by genetic factors (nature) [11]. Also, the family has been found to have an influence on self-concept of individuals [12]. In 2013 researchers found a 0.658 Pearson correlation between self-concept and social media use among college students in Malaysia [13]. In addition, the media and celebrities are also closely related factors that influence self-concept [14].

Researchers have found that gender is significant factor in the acquisition of self-identification [6]. Gender-typical behavior is brought about by individuals having their sense of self through the lens of gender [15]. According to Goldman and Penner, when examining gender differences in self-concept country-level factors are present and influential [3]. A study done among 49 countries in all the continents, found that gender-egalitarian countries have minimal gender differences in self-concept specifically academic self-concept [3].

The similar study done in 2016, found that gender and self-concept are significant in career choice and vary between countries [3]. For instance, veterinary medicine in Turkey is viewed as a masculine oriented career but in the United States it is viewed as a feminine [3]. Thus, implying that cultural perspectives on selfconcept, career choice and gender are influenced by the countrylevel factors.

Cultural stereotypes taught through socialization bring about gender differences in self-concept $[3,7]$. An individual's self- concept has been found to be a predictor of career choice. A cross-sectional study across 49 countries found gender disparities in mathematical self-concept. The females were found to have a lower mathematical self-concept compared to males [3]. As a result, the more males inclined to mathematically oriented careers than females.

Social self-concept influences the happiness and well-being of an individuals'. Females have been found to get happiness and life satisfaction from interpersonal relationships from family and friendships [7]. In comparison males get happy and satisfied with their life from their achievement specifically among students this is academic self-concept [7]. Research has also found that females had higher scores than males in the family self-concept [5]. However, another research carried out in 2010 [4] had contrasting findings; as there were no gender differences in the family self-concept; in addition to the personal self-concept [5].

There is a dearth of studies on the influence of the six dimensions of self-concept and gender on overall self-concept among private universities in Kenya. Therefore, the current study will contribute towards bridging that knowledge gap.

The aim of the current study was to investigate the influence of physical, personal, social, family, moral and academic self-concept dimensions and gender on overall self-concept among students studying either the psychology of personality or abnormal psychology courses United States International University- Africa (USIU-A).

\section{Methods}

\section{The study location and sample}

The study was carried out at a private university called United States International University-Africa (USIU-A) in Nairobi, Kenya. The USIU-A has a total population of students of 6,512: out of which $53 \%$ are females and $47 \%$ males [16].

The sample for the current was drawn purposively to yield respondents from both genders and diversity of academic majors. The students were from either the psychology of personality or abnormal psychology courses.

The sample of this study was 57 students. This is $0.875 \%$ of the total of USIU-A student population. Out of the total sample, $42(73.7 \%)$ of the respondents were female and 15 (26.3\%) male. The study was not meant to be representative of the total USIU-A student population but of the students doing the psychology or abnormal psychology courses.

Out of the total sample, $47.4 \%$ were Psychology students, $35.1 \%$ International Relations, $10.5 \%$ Criminal Justice, 3.5\% Business Administration, $1.8 \%$ Journalism and $1.8 \%$ Information and Technology Studies (IST) students.

\section{The instrument}

The current study largely utilized quantitative research methods. The Tennessee Self-concept Scale (TSCS) questionnaire and methodology was utilized. The split-half reliability score for Tennessee Self-concept Scale (TSCS) is between 0.925 and 0.945 
[4]. The TSCS Adult form has been found to be valid for research settings to investigate dimensions of self-concept [14].

The instrument TSCS: 2 second edition adult form has 82 statements/questions measuring the six aspects of self-concept: family, moral, physical, social, academic and personal selfconcepts. The statements are Likert scaled with 1-Always false, 2-Mostly false, 3-Partly false and Partly true, 4-Mostly true and 5-Always true. I decided to use the TSCS questionnaire for a number of reasons: its reliability and validity had already been established by past published studies; it was easy to administer; it facilitated gathering of information (belief, feelings, perceptions and behaviors) on the six types of self-concept; and it was affordable since it was a readymade questionnaire.

Out of the 82 TSCS statements/questions, 12 (14.6\%) were on family self-concept, 11 (13.4\%) on moral self-concept, 9 (11\%) on physical self-concept, 13 (15.9\%) on academic self-concept, 20 (24.4\%) on social self-concept and $17(20.7 \%)$ on personal selfconcept.

The questionnaire also had questions on respondent's major, gender (male or female) and year of study (freshman, sophomore, junior or senior).

In order to gather information on the overall self-concept, I added a question to the TSCS questionnaire asking respondents to rate their overall self-concept on a graduated continuous scale ranging from $0 \%$ (extremely low self-concept) to 100\% (extremely high self-concept).

In addition, I added a question asking "What are some of the ways through which a student in the university can improve their self-concept?" This question was meant to generate pragmatic suggestions from the respondents themselves on how to improve self-concept among university students.

\section{Data collection}

The data collection process involved a number of steps. In step one, permission to administer the questionnaire was sought from the USIU professor teaching psychology of personality and abnormal psychology courses in 2016. In step two, RNDKM (one of the authors) visited the classes and explained the purpose of the study; informed the students that decision to participate in the study was voluntary; those who chose to participate could stop completing the questionnaire at any point; and that decision not to participate in the study would not influence the outcome of their academic results in any way. None of the student's present declined to participate. In order to assure confidentiality, the respondents were asked not to indicate their names or student numbers on the completed questionnaires.

In the third stage, the participants were given the TSCS:2 instrument. The instrument took between 10 minutes to 15 minutes to complete.

\section{Regression models}

A total of seven regression models were estimated to model the relationship between overall self-concept and physical, family, moral, academic, social and personal self-concepts plus gender and educational major. The following Equation (1) models the relationship between overall self-concept and the twelve physical self-concept variables plus gender and educational major;

$Y=\beta_{0}+\beta_{1} X_{1}+\beta_{2} X_{2}+\beta_{3} X_{3}+\beta_{4} X_{4}+\beta_{5} X_{5}+\beta_{6} X_{6}+\beta_{7} X_{7}+\beta_{8} X_{8}+\beta_{9} X_{9}+\beta_{10} X_{10}+\beta_{11} X_{11}+\beta_{12} X_{12}+\beta_{13} X_{13}+\varepsilon \ldots \ldots \ldots \ldots . .(2)$

Where: $\beta_{0}=$ Intercept term; $X_{1}=1$ am an attractive person; $X_{2}=1$ have a healthy body; $X_{3}=1$ am full of aches and pains; $X_{4}=1$ am a sick person; $X_{5}=I$ am neither too fat nor too thin; $X_{6}=$ I should have more sex appeal; $X_{7}=1$ take good care of myself physically; $X_{8}=I$ try to be careful about my appearance; $X_{9}=I$ am not good at games and sports; $X_{10}=I$ look fine just the way I am; $X_{11}=$ Major; $X_{12}=$ Gender; $\beta_{1}$ =slope coefficient for variable $X_{1} ; \beta_{2}=$ slope coefficient for variable $X_{2} ; \beta_{3}=$ slope coefficient for variable $X_{3} ; \beta_{4}$ =slope coefficient for variable $X_{4} ; \beta_{5}$ =slope coefficient for variable $X_{5} ; \beta_{6}=$ slope coefficient for variable $X_{6} ; \beta_{7}=$ slope coefficient for variable $X_{7} ; \beta_{8}$ =slope coefficient for variable $X_{8} ; \beta_{9}=$ slope coefficient for variable $X_{9} ; \beta_{10}$ slope coefficient for variable $X_{10}$; $\beta_{11}=$ slope coefficient for variable $x_{11} ; \beta_{12}$ =slope coefficient for variable $\mathrm{X}_{11}$; and $\varepsilon=$ error term capturing measurement errors.

Equation (2) models the relationship between overall selfconcept and the thirteen family self-concept variables plus gender and educational major;

$Y=\beta_{0}+\beta_{1} X_{1}+\beta_{2} X_{2}+\beta_{3} X_{3}+\beta_{4} X_{4}+\beta_{5} X_{5}+\beta_{6} X_{6}+\beta_{7} X_{7}+\beta_{8} X_{8}+\beta_{9} X_{9}+\beta_{10} X_{10}+\beta_{11} X_{11}+\beta_{12} X_{12}+\beta_{13} X_{13}+\varepsilon \ldots \ldots \ldots \ldots . . .(2)$

Where: $\beta_{0}=$ Intercept term; $X_{1}=$ Major; $X_{2}=$ Gender; $X_{3}=1$ am a member of a happy family; $X_{4}=1$ do not act the way my family thinks I should.; $X_{5}=$ I am satisfied with my family relationships.; $X_{6}=1$ understand my family as well as I should.; $X_{7}=$ My family would always help me with any kind of trouble.; $X_{8}=1$ am not loved by my family.; $X_{9}=$ I feel that my family does not trust me.; $X_{10}=I$ treat my parents as well as I should; $X_{11}=I$ am too sensitive about the things people in my family say, $x \beta_{1}=1$ should love my family more. $X_{13}=$ I quarrel with my family. =slope coefficient for variable $X_{1} ; \beta_{2}$ =slope coefficient for variable $X_{2} ; \beta_{3}=$ slope coefficient for variable $X_{2} ; \beta_{3}$ =slope coefficient for variable $X_{3} ; \beta_{4}$ =slope coefficient for variable $X_{4} ; \beta_{5}=$ slope coefficient for variable $X_{5} ; \beta_{6}=$ slope coefficient for variable $X_{6} ; \beta_{7}$ =slope coefficient for variable $X_{7} ; \beta_{8}$ =slope coefficient for variable $X_{8} ; \beta_{9}=$ slope coefficient for variable $X_{9} ; \beta_{10}=$ slope coefficient for variable $X_{10}$; $\beta_{11}$ =slope coefficient for variable $X_{11} ; \beta_{12}$ = slope coefficient for variable $X_{12}$ and $\varepsilon=$ error term capturing measurement errors.

Equation (3) models the relationship between overall selfconcept and the thirteen moral self-concept variables plus gender and educational major;

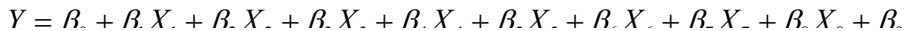

Where: $\beta_{0}=$ Intercept term; $X_{1}=I$ am an honest person.; $X_{2}=I$ wish I could be more trustworthy.; $X_{3}=$ I am satisfied with my moral behavior.; $X_{4}=$ I am a morally weak person.; $X_{5}=$ I have trouble doing the things that are right.; $X_{6}=1$ should not tell so many lies.; $X_{7}=1$ am true to my religion in my everyday actions.; $X_{8}=1$ sometimes do very bad things.; $X_{9}=1$ do what is right most of the time.; $X_{10}=1$ am a bad person.; $X_{11}=I$ am satisfied with my relationship with God.; $X_{12}=$ Major; $X_{13}=$ Gender $\beta_{1}=$ slope coefficient for variable $X_{1} ; \beta_{2}=$ slope coefficient for variable $X_{2} ; \beta_{3}=$ slope coefficient for variable $X_{3} ; \beta_{4}$ =slope coefficient for variable $X_{4} ; \beta_{5}$ =slope 
coefficient for variable $X_{5} ; \beta_{6}=$ slope coefficient for variable $X_{6} ; \beta_{7}$ =slope coefficient for variable $X_{7} ; \beta_{8}=$ slope coefficient for variable $X_{8} ; \beta_{9}$ =slope coefficient for variable $X_{9} ; \beta_{10}$ =slope coefficient for variable $X_{10} ; \beta_{11}=$ slope coefficient for variable $X_{11} ; \beta_{12}=$ slope coefficient for variable $X_{12} ; \beta_{13}$ slope coefficient for variable $X_{13}$ and $\varepsilon=$ error term capturing measurement errors.

Equation (4) models the relationship between overall selfconcept and the fourteen academic self-concept variables plus gender and educational major;

$Y=\beta_{-}+R_{X_{-}}+\beta_{-} X_{-}+\beta_{-} X_{-}+\beta_{X_{-}}+\beta_{-} X_{-}+R_{X_{-}}+\beta_{-} X_{-}+\beta_{-} X_{-}+\beta_{-} X$

Where: $\beta_{0}=$ Intercept term; $X_{1}=$ Major $X_{2}=$ Gender.; $X_{3}=$ Math is hard for me.; $X_{4}=1$ am not as smart as the people around me.; $X_{5}=I t$ is easy for me to learn new things.; $X_{6}=I$ do well at math.; $X_{7}=$ Other people think I am smart.; $X_{8}=I$ am not good at work I do.; $X_{9}=I^{\prime}$ Il never be as smart as other people.; $X_{10}=$ I like to work with numbers.; $X_{11}=1$ do not know how to work well.; $X_{12}=$ I solve my problems quite easily.; $X_{13}=$ Sometimes I put off until tomorrow what I ought to do today. $\mathrm{X}_{14}=I \mathrm{t}$ 's easy for me to understand what I read.; $\beta_{1}=$ slope coefficient for variable $X_{1} ; \beta_{2}=$ slope coefficient for variable $X_{2} ; \beta_{3}$ =slope coefficient for variable $X_{3} ; \beta_{4}=$ slope coefficient for variable $X_{4} ; \beta_{5}$ =slope coefficient for variable $X_{5} ; \beta_{6}$ =slope coefficient for variable $X_{6} ; \beta_{7}$ =slope coefficient for variable $x_{7} ; \beta_{8}=$ slope coefficient for variable $X_{8} ; \beta_{9}$ =slope coefficient for variable $X_{9} ; \beta_{10}=$ slope coefficient for variable $X_{10} ; \beta_{11}=$ slope coefficient for variable $X_{11} ; \beta_{12}$ =slope coefficient for variable $X_{12}$; $\beta_{13}$ =slope $c$ sefficient for variable $x_{13} ; \beta_{14}$ slope coefficient for variable $\mathrm{X}_{14}$; and $\varepsilon=$ error term capturing measurement errors.

Equation (5) models the relationship between overall selfconcept and the eighteen social self-concept variables plus gender and educational major;

Where: $\beta_{0}=$ Intercept term; $X_{1}=$ Major $X_{2}=$ Gender.; $X_{3}=1$ do not feel at ease with other people.; $X_{4}=1$ am a friendly person.; $X_{5}=1$ get along well with other people.; $X_{6}=1$ am cheerful person..; $X_{7}=I$ am hard to be friendly with.; $X_{8}=$ Once in a while I think of things too bad to talk about.; $X_{9}=I$ am as sociable as I want to be.; $\mathrm{X}_{10}=$ Once in a while I laugh at dirty jokes.; $\mathrm{X}_{11}=\mathrm{I}$ am satisfied with the way I treat other people.; $X_{12}=$ I ought to get along better with people.; $\mathrm{X}_{13}=$ I gossip a little at times.; $\mathrm{X}_{14}=$ I try to understand the other person's point of view.; $X_{15}=1$ am no good at all in social situations.; $X_{16}=1$ see something good in everyone I meet.; $X_{17}=1$ am as nice as I should be.; $X_{18}=I$ find it hard to talk with strangers. $\beta_{0}=$ slope coefficient for variable $x_{1} ; \beta_{2}$ =slope coefficient for variable $x_{2} ; \beta_{3}$ =slope coefficient for variable $X_{3} ; \beta_{4}=$ slope coefficient for variable $X_{4} ; \beta_{5}$ =slope coefficient for variable $X_{5} ; \beta_{6}$ =slope coefficient for variable $X_{6} ; \beta_{7}=$ slope coefficient for variable $X_{7} ; \beta_{8}=$ slope coefficient for variable $X_{8} ; \beta_{9}=$ slope coefficient for variable $X_{9} ; \beta_{10}=$ slope coefficient for variable $X_{10} ; \beta_{11}=$ slope coefficient for variable $X_{11} ; \beta_{12}$ =slope coefficient for variable $X_{12} ; \beta_{13}$ slope coefficient for variable $X_{13} ; \beta_{14}=$ slope coefficient for variable $X_{14} ; \beta_{15}$ =slope coefficient for variable $X_{15} ; \beta_{16}=$ slope coefficient for variable $X_{16} ; \beta_{17}=$ slope coefficient for variable $X_{17}$; $\beta_{18}=$ slope coefficient for variable $X_{18}$ and $\varepsilon$ =error term capturing measurement errors.
Equation (6) models the relationship between overall selfconcept and the twenty-one personal self-concept variables plus gender and educational major;

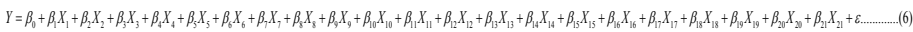

Where: $\beta_{0}=$ Intercept term; $X_{1}=$ Major $X_{2}=$ Gender.; $X_{3}=I$ am losing my mind.; $X_{4}=$ I am not the person I would like to be.; $X_{5}=1$ despise myself.; $X_{6}=I$ do not feel as well as I should.; $X_{7}=I$ am satisfied to be just what I am.; $X_{8}=I$ consider myself a sloppy person.; $X_{9}=I$ am a decent sort of person.; $X_{10}=I$ try to run away from my problems.; $X_{11}=$ I am nobody.; $X_{12}=$ get angry sometimes.; $X_{13}=I$ am a hateful person.; $X_{14}=1$ am mad at the whole world.; $X_{15}=$ Sometimes when I am not feeling well, I am cross. $X_{16}=$ Sometimes I feel like swearing.; $X_{17}=$ I feel good most of the time.; $X_{18}=$ I can always take care of myself in any situation.; $X_{19}=l ' d$ rather win a game than lose one.; $X_{20}=$ I have trouble sleeping.; $X_{21}=1$ have a lot of selfcontrol. $\beta_{0}=$ slope coefficient for variable $X_{2}$; =slope coefficient for variable $X_{1} ; \beta_{2}$ =slope coefficient for variable $X_{2} ; \beta_{3}=$ slope coefficient for variable $X_{3} ; \beta_{4}$ =slope coefficient for variable $X_{4} ; \beta_{5}=$ slope coefficient for variable $X_{5} ; \beta_{6}=$ slope coefficient for variable $X_{6} ; \beta_{7}$ =slope coefficient for variable $X_{7} ; \beta_{8}=$ slope coefficient for variable $X_{8} ; \beta_{9}$ =slope coefficient for variable $X_{9}$; $\beta_{10}$ =slope coefficient for variable $X_{10} ; \beta_{12}$ =slope coefficient for variable $X_{12} ; \beta_{13}$ =slope coefficient for variable $X_{13} ; \beta_{14}=$ slope coefficient for variable $X_{14} ; \beta_{15}$ =slope coefficient for variable $X_{15} ; \beta_{16}=$ slope coefficient for variable $X_{16} ; \beta_{17}=$ slope coefficient for variable $X_{17} ; \beta_{18}$ =slope coefficient for variable $X_{18} ; \beta_{19}=$ slope coefficient for variable $X_{19} ; \beta_{20}=$ slope coefficient for variable $X_{20}$; $\beta_{21}$ slope coefficient for variable $X_{21}$ and $\varepsilon=$ error term capturing measurement errors.

\section{Analysis}

The data were analyzed using the Statistical Package for Social Sciences (SPSS 24.0 version). The correlation coefficients and regressions were computed utilizing the SPSS. The analysis was to investigate the statistical relationship between gender and self-concept.

The following hypotheses were tested at $5 \%$ significance level:

- Null hypothesis $\left(\mathrm{H}_{0}\right)$ : There is no statistically significant relationship between gender and types of self-concept, i.e., $H_{0}: r=0$. Where $r$ stands for the Pearson Correlation Coefficient.

- Alternative hypothesis $\left(\mathrm{H}_{\mathrm{A}}\right)$ : There is statistically significant relationship between gender and types of self-concept, i.e., $H_{A}: r \neq 0$.

The test of differences of means was done for the 82 statements in the TSCS. The hypotheses were tested using t-distribution test at $5 \%$ level of significance for a two tailed test. The critical t-statistic from the Student's t-distribution table at 56 degrees of freedom (i.e., 57 minus the variable under consideration) and $5 \%$ level of significance was 1.96 . Thus, whenever the computed t-statistic generated by SPSS was greater than the critical t-statistic (1.96) the null hypothesis was rejected.

In addition to the correlations, the following regression model 
was estimated to ascertain the relationship between overall self-concept and gender: $Y=67.619+6.381$ Gender . Where: $Y=$ overall self-concept, $\alpha=$ constant/intercept term, $\beta=$ the regression coefficient, $X=$ gender ( $0=$ female and $1=$ male) and $E=$ error (capturing measurement errors and omitted variables).

\section{Results}

The adjusted R Square for physical self-concept was 25.8\%; implying that the 10 physical self-concept variables plus gender and education major variables explained $25.8 \%$ of the variations in overall self-concept.

\section{Physical self-concept}

Table 1 shows results of the regression of overall self-concept against, coefficients for variables "I am an attractive person", "I have a healthy body", "I am full of aches and pains", "I am a sick person", "I should have more sex appeal", "I try to be careful about my appearance", "I am not good at games and sports", and "I look fine just the way I am" had a positive sign. This implies that they impact positively on the overall self-concept. (Table 1)

The coefficients for variables "I am neither too fat nor too thin" and "I take good care of myself physically" took a negative sign (Table 1). Thus, showing that they negatively impacted the overall self-concept.

The computed t-statistic of the independent variable "I try to be careful about my appearance" was 4.031; which was greater than the critical t-value of 1.960. This implies that the coefficient for this variable was statistically significant at $95 \%$ confidence level. The variable also took a positive sign-implying a direct relationship with overall self-concept.

The coefficients for the other 9 variables were not statistically significant at $95 \%$ confidence level.

\section{Family self-concept}

The adjusted R Square for family self-concept was 36.3\%; implying that the 13 family self-concept variables plus gender and major variables explained $36.3 \%$ of the variations in overall selfconcept. Table 2 presents regression results of the relationship between overall self-concept and family self-concept variables. The coefficients for variables "I am a member of a happy family", "I do not act the way my family thinks I should", "I am satisfied with my family relationships", and "I should love my family more" had a positive sign. This implies that they impact positively on the overall self-concept. (Table 2)

The coefficients for variables, "I understand my family as well as I should", "My family would always help me with any kind of trouble", "I am not loved by my family", "I feel that my family does not trust me", "I treat my parents as well as I should", "I am too sensitive about the things people in my family say" and "I quarrel with my family" have negative signs (Table 2). Thus, showing that they negatively impacted the overall self-concept.

Computed t-statistic of the independent variable "I should love my family more" was 2.484; which was greater than the critical t-value of 1.960. This implies that the coefficient for this variable was statistically significant at $95 \%$ confidence level. It also took a positive sign.

The coefficients for the other 10 family self-concept variables were not statistically significant.

\section{Moral self-concept}

Table 3 portrays regression results for the relationship between overall self-concept and the explanatory variables, i.e., 13 moral self-concept variables plus gender and education major variables. The adjusted $\mathrm{R}$ Square for moral self-concept was 26.4\%; implying that the 13 moral self-concept, gender and major variables explained $26.4 \%$ of the variations in overall selfconcept. (Table 3)

The coefficients for variables "I am an honest person", "I wish I could be more trustworthy", "I have trouble doing the things that are right", "I am true to my religion in my everyday actions",

Table 1 Relationship between overall self-concept and physical self-concept.

\begin{tabular}{|c|c|c|c|c|c|}
\hline \multirow{2}{*}{ Model } & \multicolumn{2}{|c|}{ Unstandardized Coefficients } & Standardized Coefficients & \multirow{2}{*}{$\mathbf{t}$} & \multirow{2}{*}{ Sig. } \\
\hline & B & Std. Error & Beta & & \\
\hline (Constant) & 49.833 & 7.579 & -- & 6.576 & 0.000 \\
\hline I am an attractive person $\left(X_{1}\right)$ & 2.784 & 5.278 & 0.071 & 0.527 & 0.601 \\
\hline I have a healthy body $\left(X_{2}\right)$ & 4.849 & 5.295 & 0.124 & 0.916 & 0.365 \\
\hline I am full of aches and pains $\left(X_{3}\right)$ & 1.308 & 5.152 & 0.034 & 0.254 & 0.801 \\
\hline I am a sick person $\left(X_{4}\right)$ & 5.434 & 7.039 & 0.103 & 0.772 & 0.445 \\
\hline I am neither too fat nor too thin $\left(X_{5}\right)$ & -12.419 & 10.275 & -0.172 & -1.209 & 0.234 \\
\hline I should have more sex appeal $\left(X_{6}\right)$ & 3.586 & 5.187 & 0.100 & 0.691 & 0.493 \\
\hline I take good care of myself physically $\left(\mathrm{X}_{7}\right)$ & -7.194 & 5.185 & -0.209 & -1.387 & 0.173 \\
\hline I try to be careful about my appearance $\left(\mathrm{X}_{8}\right)$ & 19.638 & 4.872 & 0.581 & 4.031 & 0.000 \\
\hline I am not good at games and sports $\left(X_{g}\right)$ & 1.886 & 4.812 & 0.055 & 0.392 & 0.697 \\
\hline I look fine just the way I am $\left(X_{10}\right)$ & 2.423 & 5.368 & 0.065 & 0.451 & 0.654 \\
\hline Major $\left(X_{11}\right)$ & 8.177 & 4.999 & 0.242 & 1.636 & 0.110 \\
\hline Gender $\left(X_{12}\right)$ & -0.971 & 5.548 & $0-.026$ & -0.175 & 0.862 \\
\hline
\end{tabular}


Table 2 Relationship between overall self-concept and family self-concept.

\begin{tabular}{|c|c|c|c|c|c|}
\hline \multirow{2}{*}{ Model } & \multicolumn{2}{|c|}{ Unstandardized Coefficients } & \multirow{2}{*}{$\begin{array}{c}\text { Standardized Coefficients } \\
\text { Beta }\end{array}$} & \multirow{2}{*}{$\mathbf{t}$} & \multirow{2}{*}{ Sig. } \\
\hline & B & Std. Error & & & \\
\hline (Constant) & 62.090 & 6.365 & -- & 9.754 & 0.000 \\
\hline Major $\left(X_{1}\right)$ & 8.028 & 4.381 & 0.244 & 1.832 & 0.075 \\
\hline Gender $\left(\mathrm{X}_{2}\right)$ & 4.185 & 4.500 & 0.114 & 0.930 & 0.358 \\
\hline I am a member of a happy family. $\left(X_{3}\right)$ & 5.126 & 5.568 & 0.143 & 0.921 & 0.363 \\
\hline I do not act the way my family thinks I should. $\left(X_{4}\right)$ & .589 & 5.806 & 0.012 & 0.101 & 0.920 \\
\hline I am satisfied with my family relationships. $\left(X_{5}\right)$ & 1.738 & 4.476 & 0.049 & 0.388 & 0.700 \\
\hline I understand my family as well as I should. $\left(X_{6}\right)$ & -9.575 & 5.307 & -0.255 & -1.804 & 0.079 \\
\hline My family would always help me with any kind of trouble. $\left(X_{7}\right)$ & -10.457 & 11.131 & -0.172 & -0.939 & 0.354 \\
\hline I am not loved by my family. $\left(X_{8}\right)$ & -18.209 & 14.386 & -0.216 & -1.266 & 0.214 \\
\hline I feel that my family does not trust me. $\left(X_{g}\right)$ & -1.938 & 10.766 & -0.028 & -0.180 & 0.858 \\
\hline I treat my parents as well as I should. $\left(\mathrm{X}_{10}\right)$ & -2.928 & 4.303 & -0.082 & -0.680 & 0.500 \\
\hline I am too sensitive about the things people in my family say. $\left(X_{11}\right)$ & -1.984 & 4.196 & -0.061 & -0.473 & 0.639 \\
\hline I should love my family more. $\left(\mathrm{X}_{12}\right)$ & 10.380 & 4.179 & 0.310 & 2.484 & 0.018 \\
\hline I quarrel with my family. $\left(\mathrm{X}_{13}\right)$ & -4.064 & 4.260 & -0.124 & -0.954 & 0.346 \\
\hline
\end{tabular}

Table 3 Relationship between overall self-concept and moral self-concept Coefficients ${ }^{\mathrm{a}}$.

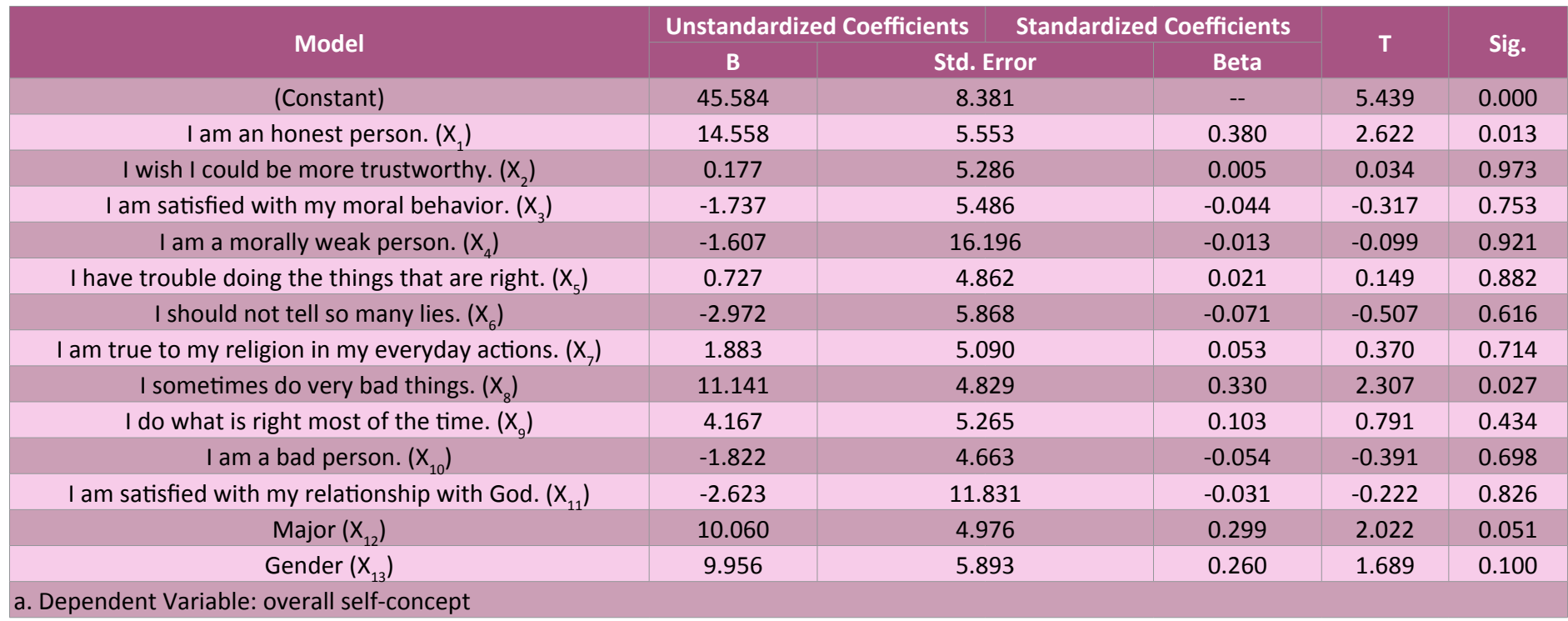

"I sometimes do very bad things", and "I do what is right most of the time" had positive signs (Table 3). This implies that they impact positively on the overall self-concept.

The coefficients for variables, "I am satisfied with my moral behavior", "I am a morally weak person", "I should not tell so many lies", "I am a bad person" and "I am satisfied with my relationship with God." Thus, showing that the variables with a negative sign, negatively impacted the overall self-concept (Table 3).

The computed t-statistic of the independent variables "I am an honest person" was 2.622 and "I sometimes do very bad things" was 2.307; which were greater than the critical t-value of 1.960. This implies that the coefficient for these variables were statistically significant at $95 \%$ confidence level. The coefficients for the other 9 variables were not statistically significant.

\section{Academic self-concept}

Table 4 shows the regression results for the relationship between overall self-concept and 12 of the academic self-concept variables plus those of gender and education major. The adjusted R Square for academic self-concept was $11.1 \%$; implying that the 14 academic self-concept, gender and major variables explained $11.1 \%$ of the variations in overall self-concept (Table 4).

The coefficients for variables "I am not as smart as the people around me", "I am not good at work I do", "I do not know how to work well" and "It's easy for me to understand what I read" had positive signs (Table 4). This suggests that they impact positively on the overall self-concept.

In Table 4 coefficients for variables, "Math is hard for me.", "It is easy for me to learn new things", "I do well at math", "Other 
people think I am smart" "I'Il never be as smart as other people", "I like to work with numbers", "I solve my problems quite easily" and "Sometimes I put off until tomorrow what I ought to do today" had negative signs. Therefore, these variables negatively impacted the overall self-concept.

In the academic self-concept model, none of the independent variable coefficients had a computed t-statistic greater than the critical t-value of 1.960. This indicates that the coefficients for the academic self-concept variables were not statistically significant at $95 \%$ confidence level.

\section{Social self-concept}

Table 5 depicts the relationship between overall self-concept and the 16 social self-concept variables and those of gender and educational major. The adjusted $\mathrm{R}$ Square for social self-concept was $5.2 \%$; implying that the 16 social self-concept, gender and major variables explained $5.2 \%$ of the variations in overall selfconcept. (Table 5)

The coefficients for variables "I am a friendly person", "I get along well with other people", "I am hard to be friendly with", "Once in a while I laugh at dirty jokes", "I ought to get along better with people", "I am no good at all in social situations", "I see something good in everyone I meet", "I am as nice as I should be" and "I find it hard to talk with strangers" had positive sign. This implies that they impact positively on the overall self-concept.

The coefficients for variables "Once in a while I think of things too bad to talk about", "I do not feel at ease with other people", "I am cheerful person", "I am as sociable as I want to be" "I am satisfied with the way I treat other people", "I gossip a little at times" and "I try to understand the other person's point of view" had negative signs. Therefore, these variables negatively impacted overall self-concept.

None of the variable coefficients in the social self-concept model had computed t-statistic of greater than the critical t-value of 1.960. This indicates that the coefficients for the social selfconcept variables were not statistically significant at $95 \%$ confidence level.

\section{Personal self-concept}

Table 6 presents the personal self-concept model regression results. The adjusted $\mathrm{R}$ Square for social self-concept was $46.8 \%$; implying that the 19-personal self-concept, gender and major variables explained $46.8 \%$ of the variations in overall self-concept (Table 6).

The coefficients for variables "I am losing my mind", "I am not the person I would like to be", "I am satisfied to be just what I am", "I consider myself a sloppy person", "I am a decent sort of person", "I am nobody", "I get angry sometimes", "I am a hateful person", "I am mad at the whole world", "Sometimes when I am not feeling well, I am cross", "I can always take care of myself in any situation" and "I'd rather win a game than lose one" had positive signs (Table 6). This suggests that they impact positively on the overall self-concept.

The coefficients for the variables "I do not feel as well as I should", "I do not feel at ease with other people", "I despise myself", "I try to run away from my problems" "Sometimes I feel like swearing", "I feel good most of the time", "I have trouble sleeping" and "I have a lot of self-control" had negative signs. This means that these variables impacted negatively on overall self-concept.

Table 4 Relationship between overall self-concept and academic self-concept Coefficients ${ }^{a}$.

\begin{tabular}{|c|c|c|c|c|c|}
\hline \multirow[t]{2}{*}{ Model } & $\begin{array}{l}\text { Unstandardized } \\
\text { Coefficients }\end{array}$ & \multicolumn{2}{|c|}{ Standardized Coefficients } & \multirow[t]{2}{*}{$\mathbf{t}$} & \multirow[t]{2}{*}{ Sig. } \\
\hline & B & Std. Error & Beta & & \\
\hline (Constant) & 65.657 & 9.967 & -- & 6.587 & 0.000 \\
\hline Major $\left(X_{1}\right)$ & 4.190 & 5.735 & 0.125 & 0.731 & 0.470 \\
\hline Gender $\left(X_{2}\right)$ & 3.790 & 6.070 & 0.098 & 0.624 & 0.536 \\
\hline Math is hard for me. (X3) & -5.128 & 7.240 & -0.121 & -0.708 & 0.483 \\
\hline I am not as smart as the people around me. $\left(\mathrm{X}_{4}\right)$ & 2.708 & 8.186 & 0.064 & 0.331 & 0.743 \\
\hline It is easy for me to learn new things. $\left(X_{5}\right)$ & -17.937 & 10.532 & -0.250 & -1.703 & 0.097 \\
\hline I do well at math. $\left(X_{6}\right)$ & -13.769 & 12.188 & -0.192 & -1.130 & 0.266 \\
\hline Other people think I am smart. $\left(X_{7}\right)$ & -2.014 & 4.985 & -0.059 & -.404 & .689 \\
\hline I am not good at work I do. $\left(\mathrm{X}_{8}\right)$ & 10.113 & 14.958 & 0.116 & 0.676 & 0.503 \\
\hline$I^{\prime}$ ll never be as smart as other people. $\left(X_{9}\right)$ & -7.811 & 5.985 & -0.225 & -1.305 & 0.200 \\
\hline I like to work with numbers. $\left(X_{10}\right)$ & -3.939 & 5.246 & -0.117 & -0.751 & 0.457 \\
\hline I do not know how to work well. $\left(\mathrm{X}_{11}\right)$ & 11.982 & 6.216 & 0.341 & 1.928 & 0.062 \\
\hline I solve my problems quite easily. $\left(X_{12}\right)$ & -3.122 & 6.124 & -0.081 & -0.510 & 0.613 \\
\hline Sometimes I put off until tomorrow what I ought to do today. $\left(X_{13}\right)$ & -4.167 & 5.903 & -0.115 & -0.706 & 0.485 \\
\hline It's easy for me to understand what I read. $\left(\mathrm{X}_{14}\right)$ & 2.423 & 5.865 & 0.072 & 0.413 & 0.682 \\
\hline
\end{tabular}


Table 5 Relationship between overall self-concept and social self-concept Coefficients ${ }^{a}$.

\begin{tabular}{|c|c|c|c|c|c|}
\hline \multirow{2}{*}{ Model } & \multicolumn{2}{|c|}{ Unstandardized Coefficients } & \multirow{2}{*}{$\begin{array}{c}\text { Standardized Coefficients } \\
\text { Beta }\end{array}$} & \multirow[t]{2}{*}{$t$} & \multirow{2}{*}{ Sig. } \\
\hline & B & Std. Error & & & \\
\hline (Constant) & 58.769 & 10.989 & -- & 5.348 & 0.000 \\
\hline Major $\left(X_{1}\right)$ & 1.899 & 6.294 & 0.059 & 0.302 & 0.765 \\
\hline Gender $\left(X_{2}\right)$ & 4.617 & 6.857 & 0.125 & 0.673 & 0.506 \\
\hline I do not feel at ease with other people. $\left(X_{3}\right)$ & -3.745 & 8.804 & -0.098 & -0.425 & 0.674 \\
\hline I am a friendly person. $\left(X_{4}\right)$ & 0.015 & 6.155 & 0.000 & 0.003 & 0.998 \\
\hline I get along well with other people. $\left(X_{5}\right)$ & 2.453 & 8.102 & 0.075 & 0.303 & 0.764 \\
\hline I am cheerful person. $\left(X_{6}\right)$ & -6.884 & 8.432 & -0.195 & -0.816 & 0.421 \\
\hline I am hard to be friendly with. $\left(X_{7}\right)$ & 9.165 & 19.303 & 0.082 & 0.475 & 0.639 \\
\hline Once in a while I think of things too bad to talk about. (X8) & -12.372 & 16.605 & -0.155 & -0.745 & 0.462 \\
\hline I am as sociable as I want to be. (X9) & -9.183 & 17.293 & -0.115 & -0.531 & 0.600 \\
\hline Once in a while I laugh at dirty jokes. $\left(\mathrm{X}_{10}\right)$ & 13.858 & 7.461 & 0.400 & 1.857 & 0.074 \\
\hline I am satisfied with the way I treat other people. $\left(X_{11}\right)$ & -23.406 & 15.066 & -0.292 & -1.554 & 0.132 \\
\hline I ought to get along better with people. $\left(X_{12}\right)$ & 7.156 & 6.243 & 0.221 & 1.146 & 0.261 \\
\hline I gossip a little at times. $\left(X_{13}\right)$ & -4.051 & 6.847 & -0.120 & -0.592 & 0.559 \\
\hline I try to understand the other person's point of view. $\left(X_{14}\right)$ & -8.104 & 9.249 & -0.224 & -0.876 & 0.388 \\
\hline I am no good at all in social situations. $\left(\mathrm{X}_{15}\right)$ & 4.263 & 7.671 & 0.123 & 0.556 & 0.583 \\
\hline I see something good in everyone I meet. (X16) & 4.263 & 7.671 & 0.123 & 0.556 & 0.583 \\
\hline I am as nice as I should be. $\left(X_{17}\right)$ & 4.343 & 7.548 & 0.123 & 0.575 & 0.570 \\
\hline I find it hard to talk with strangers. $\left(\mathrm{X}_{18}\right)$ & 2.318 & 6.222 & 0.072 & 0.373 & 0.712 \\
\hline
\end{tabular}

a. Dependent Variable: overall self- concept

Table 6 Relationship between overall self-concept and personal self-concept Coefficients ${ }^{\mathrm{a}}$.

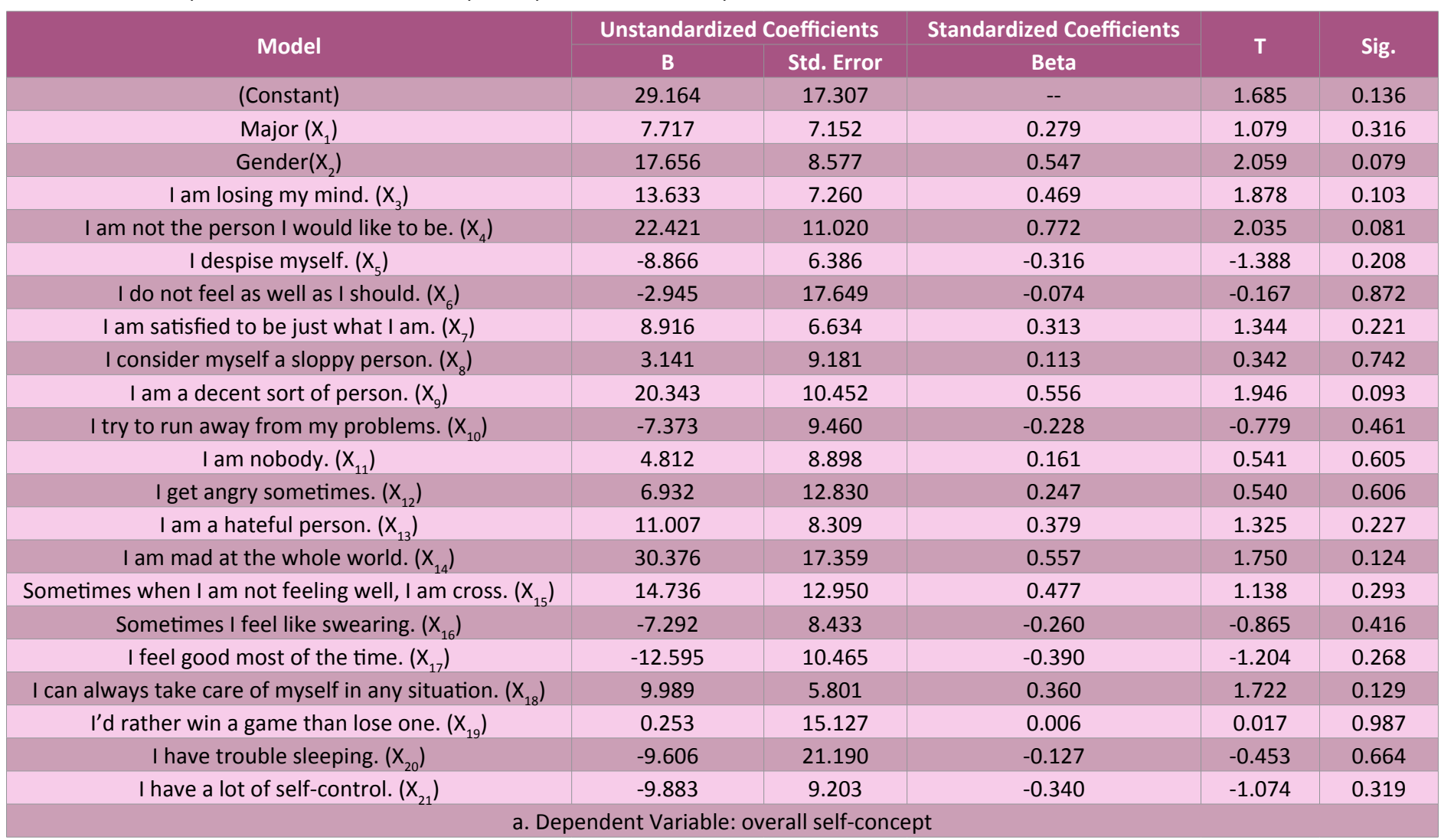

The computed t-statistics "I am not the person I would like to be" and gender variables were greater than the critical t-statistic value of 1.960 . This indicates that the coefficients for the remaining 18 personal self-concept variable and education major were not statistically significant at $95 \%$ confidence level.

\section{Overall self-concept and gender}

The regression of overall self-concept against gender produced the following result: $Y=67.619+6.381$ Gender The adjusted $\mathrm{R}$-squared is $1.2 \%$; implying that Gender variable explains only $1.2 \%$ of the total variations in students overall self-concept. 
The gender variable coefficient shows that as gender changes from female (0) to male (1) overall self-concept increases by $6.381 \%$. The computed t-statistic was 1.297 ; which was less than critical t-value of 1.96. This means that gender variable coefficient was not statistically significant at $95 \%$ confidence level.

\section{Discussion}

\section{The relationship between gender and different types of self-concept of students}

Females rate themselves higher than males in the dimension of family self-concept [3]; implying that female students had a better relationship with their families than the male students. In contrast, the current study found no statistically significant relationship between gender and family self-concept. This is consistent with studies done in 2010 and 2016, where the researchers found no gender differences in the family selfconcept $[4,6]$.

The current study found no statistically significant relationship between gender and moral self-concept. However, a study done in China found that there were significant gender differences in the moral self-concept and self-identity dimensions of selfconcept [6]. The researchers have stated that for the moral selfdimension, females rate themselves higher than the males $[4,6]$.

This study found no statistically significant relationship between gender and physical self-concept. This contradicts findings of some other researchers who found that for the physical selfconcept dimension males expressed more satisfaction in their strength than the females $[4,5]$. This implies that the students believed males are more physically able than females.

In Kenya, a study among secondary school students found gender differences in academic self-concept [17]. The findings showed that male students had a higher mathematical selfconcept than females [18]. An individual's academic self-concept among college students determined their performance, goals and success [19]. Positive self-concept has been found to be beneficial for performance and career path [19]. Albert and Dahling, discovered an individual's academic self-concept has a positive influence on his or her performance which was measured by grade point average (GPA) [19].

In addition, high academic self-concept or achievement has varied effects on females and males. For females' high academic achievement results in more life satisfaction but not happiness for males it is the opposite [7]. On the other hand, males' high academic achievement brings happiness and not life satisfaction [7]. However, the current study found no statistically significant relationship between gender and academic self-concept. Females who are in technical fields have had to go against the negative cultural stereotypes through collaborative learning in order to succeed in male oriented careers $[3,20]$.

Social self-concept which involves having close friends and healthy interpersonal relationships has been found to have a significant relation with life satisfaction and happiness [7]. For the social self-concept the current study found similar results with other studies. There are no statistically significant gender differences in social self-concept. This was similar with a study done in 2002, where researchers found no statistically significant gender differences in the dimension of social self-concept [5].

There are no gender differences in personal self-concept. However, the current study found that a university student felt that they were not the person they would like to be at the present time of the study. Thus, implying that they would like to be different compared to their current state. In addition, a study done in China among university students found the same; no gender differences in the personal self-concept [4].

\section{The relationship between gender and overall self-concept}

Gender did have significant effects on self-concept among university students [5]. Males have a higher overall self-concept than females. This study found that as gender changes from female (0) to male (1) overall self-concept increases by $6.381 \%$. This implies that males have a higher overall self-concept than females. In 2016, a study found the males had a higher overall self-concept than the females [10]. In 2010, Zhang stated that males are more satisfied with themselves than males [5]. This finding is concurrent with this study as the males are more content with the 'self-concept.'

However, another study done among undergraduates disagreed with the findings from other studies that claimed gender does influence self-concept [21].

\section{The ways to improve self-concept}

In this study most of the suggested ways of improving selfconcept were similar between the genders. The common recommendations between the sexes included socialization with people such as peers or professors, knowing strengths and weaknesses, self-acceptance, and reading. However, in this study $16.7 \%$ of female students stated 'I do not know' how to improve their self-concept. This shows concurrent with the change seen when looking at the overall self-concept decrease by $-6.81 \%$ as we move from male to female.

Various researches had similar recommendations including interactions with parents or supportive figures such as teachers or lecturers could improve self-concept [9]. Another suggestion for improving self-concept included creation of campus based programs that will encourage self-acceptance with one's strengths and weaknesses. In addition, the same study found reading of positive materials and engaging in good peer interaction are some ways self-concept can be improved [9].

In the USIU-A case there should be no gender discrimination in the interventions for improving the dimensions of self-concept. For instance, interventions which are different due to the gender of an individual. The reason being the current study found no statistically significant gender difference in the different dimensions of self-concept.

Given the overall self-concept was higher among male students than females. The university could probably prioritize 
interventions aimed at improving the overall self-concept of females so as to strike gender balance.

The suggestions presented by participants in this study should be considered when designing interventions for improving selfconcept among university students. For instance, inclusion of a topic on ways of improving self-concept in general university induction course might equip students with knowledge and skills to bolster overall self-concept.

\section{Limitations of the Study}

The study potentially has three limitations. First, the current study utilized a non-probability sampling method specifically purposive sampling. Thus, even though the findings are representative of the students studying either the psychology of personality or abnormal psychology courses, they are not generalizable to the entire student population of USIU-A.

Second, the TSCS instrument used to collect data for the current study was originally developed for use in the United States, but has since been applied in European and Asian continents. Thus, critiques may argue that the instrument might not be fully culturally relevant for an African context. However, the reader should note that we used the TSCS as there are no self-concept instruments developed specifically for African contexts. In addition, such criticism might not be valid because none of the study participants indicated that the instrument or some of its items were irrelevant.

\section{References}

1 Grecas V (1982) The self concept. Annu Rev Sociol 8: 1-33.

2 Lindgren KP, NeighborsC, Gasser ML, Ramirez JJ, Cvencek, DA (2017) Review of implicit and explicit substance self-concept as a predictor of alcohol and tobacco use and misuse. Am J Drug Alcohol Abuse 43 : 237-246.

3 Goldman AD, Penner AM (2016) Exploring international gender differences in mathematics self-concept. Int J Adolesc Youth 21: 403-418

4 Zhang X (2010) The study of university students self concept. J Stud Int Educ 3: 83-86.

5 Lin KL, Cobiac L, Skrzypiec G (2002) Gender differences in eating behavior and social self concept among Malaysian university students. Mal J Nutr 8: 75-98.

6 Chui WH, Wong MY (2016) Gender differences in happiness and life satisfaction among adolescents in Hong Kong: Relationships and self-concept. Social Indicators Res 125: 1035-1051.

7 Zhang L (2016) Research on the relationship between self concept and subjective well-being of Normal University Students. Int J Innov Educ Res. 4: 79-87.

8 Robins RW, Trzeniewski KH (2005) Self-esteem development across the lifespan. Am J Psychiatry 14: 158-162.

9 Strenke JC (2010) Self-concept and self-esteem in adolescents with learning disabilities. A research paper submitted in partial fulfillment of the requirements for the masters of science in education degree.
Furthermore, according to Wikipedia there are thousands of ethnic groups in Africa, each within its own language (or dialect of a language) and culture [22]. It would be practically impossible to develop a self-concept instrument that would be universally valid to all those cultures. Therefore, pragmatism demands considered application of instruments, such as TSCS, whose reliability and validity has been demonstrated in North America, Europe, and Asia.

Third, critiques might argue that the sample size too limited to make generalizations to the entire USIU-A student populations. However, as we have explained in the methods section of this paper, our study was not meant to be representative of the total USIU-A student population but of the students doing the psychology or abnormal psychology courses. Therefore, in that context the criticism might not be fully valid.

\section{Conclusion}

This study explored the self-concept of undergraduate students at USIU-A and the ways it can be improved. The study found no statistically significant relationship between gender and the different dimensions of self-concept. However, males were found to have a higher overall self-concept than female undergraduate students. There are tentative indications from the current study that self-concept can be improved through campus based programs aimed at increasing positive self-concept among students.

School of psychology, The Graduate School. Wisconsin: University of Wisconsin-Stout, USA.

10 Ahad R, Ara S, Shah SA (2016) Self-concept and aggression among institutionalized orphans of Kashmir. The Int J Indian Psychol 3: 104-116

11 Neiss MB, Stevenson J, Sedikides C, Kumashiro M, Finkel EJ, et al. (2005) Executive self, self-esteem, and negative affectivity: Relations at the phenotypic and genotypic level. J Pers Soc Psychol. 89: 593-606.

12 Dailey RM (2009) Confirmation from family members: Parent and sibling contributions to adolescent psychosocial adjustment. West $J$ Commun 73: 273-299.

13 Sponcil M, Gitimu P (2013) Use of social media by college students: Relationship to communication and self concept. J Technol Res 4: 1-13.

14 Swami V, Chamorro-Premuzic T, Mastor K, Siran FH, Said MMM, et al. (2010) Celebrity worship among university students in Malaysia: A methodological contribution to the celebrity attitude scale. European Psychol 16: 334-342.

15 Baron AS, Schmader T, Cvencek D, Meltzoff AN (2014) The gendered self-concept: How implicit gender stereotypes and attitudes shape self-definition. In: Leman PJ, Tenenbaum HR (eds.), Gender and development (109-132). Sussex: Psychology Press, UK.

16 United States International University, Africa (USIU-A): Fall 2014 Fact Sheet. Nairobi: USIU-A; 2014.

17 Bishop SL, Walling DP (1997) The Emperor's clothes: Assessing the validity of scores on the tennessee self-concept scale. Educ. Psychol Meas 57: 150-163. 
18 Githua BN, Mwangi JG (2003) Students' mathematics self-concept and motivation to Learn mathematics: Relationship and gender differences among Kenya's secondary-school students in Nairobi and rift valley provinces. Int J Educ Dev 23: 487-499.

19 Albert MA, Dahling JJ (2016) Learning goal orientation and locus of control interact to predict academic self-concept and academic performance in college students. Pers Individ Dif 97: 245-248.

20 Stout J, Tamer B (2016) Collaborative learning eliminates the negative impact of gender stereotypes on women's self-concept. In Proceedings of the $47^{\text {th }}$ ACM Technical Symposium on Computing Science Education. p. 496-496.

21 Rubie-Davies CM, Lee K (2013) Self- concept of students in higher education: Are there differences by faculty and gender? Educational studies 39: 56-67.

22 https://en.wikipedia.org/wiki/List_of_ethnic_groups_of_Africa. Accessed on 25 June 2017 at 20 h44. 